Introduction The use of drugs of abuse during pregnancy is a public health problem, with deleterious consequences for the mother, her son, family and society effects. The seriousness of the problem and the lack of data concerning the use of drugs by pregnant women in our maternity motivated us to design this study.

Objectives To identify among pregnant women admitted to the maternity HEAC users of licit and illicit drugs through selfdeclaration.

Method A descriptive, cross-sectional study period August 1, 2013 a January 3, 2014. Questionnaire was applied during the hospital postpartum women, after signing an informed consent.

Results 1055 women were studied, of these 266 (25.21\%) were users of drugs of abuse. Among the women who reported using any drugs, were identified: tobacco (36.46\%), alcohol (27.81\%), cocaine $(5.6 \%)$ and marijuana $(2.2 \%)$. The average age of the group of drug users was 25.49 years, while the non-users was 24.81 years. The prevalence of drug use among adolescents was $18.04 \%$. The children of drug users $7.5 \%$ had required neonatal intensive care. There was no statistical difference in relation to perinatal asphyxia among a group of users and non- drug users.

Conclusion Considering that the identification of these women was only through self declaration of the use of licit and illicit drugs, it becomes even more concerning the current situation with regard to drug use by pregnant women, since this is probably just the tip of a large iceberg, we need to know so we can meet.

\section{P0-0723 THE OUTCOMES OF TRIPLETS AND QUADRUPLETS BORN IN A SINGLE LEVEL III CENTRE OVER A 10 YEAR PERIOD}

${ }^{1} \mathrm{~A}$ Walsh, ${ }^{2} \mathrm{~A}$ Martin, ${ }^{1} \mathrm{~J}$ Miletin. ${ }^{1}$ Neonatology, Coombe Women and Infants University Hospital, Dublin, Ireland; ${ }^{2}$ Obstetrics and Gynaecology, Coombe Women and Infants University Hospital, Dublin, Ireland

\subsection{6/archdischild-2014-307384.1358}

Background Multiple pregnancies are an increasing entity worldwide. This is associated with an increase in the number of pregnancies complicated by preterm birth and intrauterine growth restriction, which in turn results in higher infant mortality and morbidity rates. An increased risk of cerebral palsy in multiples has been reported, being higher the higher the number of foetuses.

Aims and methods The primary aim of our retrospective study was to determine two year outcomes of triplets and quadruplets born in the Coombe Women and Infants University hospital (CWIUH) over a ten year period and in particular the need for early intervention services. A retrospective chart review of all triplets and quadruplets born between January 2002 and December 2011 was performed.

Results 125 infants from triplet pregnancies and eight infants from quadruplet pregnancies were live born in CWIUH during this period. One chart was unavailable for analysis. Therefore 132 infants were included in the study. Median gestational age was $33+2(26+2$ to $36+2)$ weeks. Median birth weight was 1800 (620 to 2960 ) g. The median length of stay in our neonatal unit was 23 (0 to 91) days. Two babies died at two months of age. Four (3\%) were referred to early intervention services, one with spastic quadriplegia and three with mild left hemiplegia. Eleven $(8 \%)$ were followed up by a community paediatrician following discharge from the neonatal clinic at two years of age. Conclusion To our knowledge this is the first study to look at the outcomes of triplets and quadruplets in Ireland. Our outcomes are similar to those reported in the international literature which quotes an incidence of cerebral palsy in triplets of approximately $4 \%$.

\section{PO-0724 AUTONOMIC AND BEHAVIOURAL STRESS RESPONSES IN LOW WEIGHT PRETERM INFANTS DURING NURSE HANDLING IN THE NICU}

${ }^{1} \underline{V}$ Zeiner, ${ }^{1} \mathrm{H}$ Storm, ${ }^{2} \mathrm{~K}$ Doheny. 'Instiute of Clinical Medicine, Simulation Center, Oslo, Norway; ${ }^{2}$ Pediatrics, College of Medicine, Hershey, USA

\subsection{6/archdischild-2014-307384.1359}

Background and aims Preterm infants should avoid stressful events, due to their immature brain and vascular structures. The purpose of this observational study was to investigate stress responses to nurse handling in the NICU.

Methods Fifteen male and fifteen female infants, gestational age $32,7$ ( $\pm 1,48)$ weeks and birth weight $1880( \pm 409)$ grams, at postnatal day 5-7 were observed during nursing care and diaper change. Standard physiological measurements; heart rate (HR), respiratory rate (RR), and skin conductance response frequency (SCR/sec), and NIDCAP ${ }^{\circ}$ behavioural stress cues; facial, visceral, motor, attentional, and self-consoling were recorded before and during care. Non-parametric Wilcoxon was used. Results There were statistical differences for physiological and behavioural measures from before to during the care:

\begin{tabular}{|c|c|c|c|}
\hline Parameter & Before & During & $\mathrm{p}$-value \\
\hline $\mathrm{SCR} / \mathrm{sec}$ & $0,06( \pm 0,05)$ & $0,13( \pm 0,07)$ & 0,000 \\
\hline $\mathrm{RR}$ & $49,8( \pm 14,9)$ & $75,7( \pm 13,0)$ & 0,000 \\
\hline$H R$ & $151,8( \pm 10,1)$ & $173,9( \pm 11,3)$ & 0.000 \\
\hline NIDCAP® behaviours & $24,08( \pm 12,64)$ & $50,63( \pm 21,5)$ & 0.002 \\
\hline - Facial cues & $1,0( \pm 1,54)$ & $2,13( \pm 3,5)$ & NS \\
\hline - Visceral cues & $1,17( \pm 1,95)$ & $3,27( \pm 4,51)$ & NS \\
\hline - Motor cues & $19,0( \pm 11,72)$ & $34,97( \pm 14,62)$ & 0,002 \\
\hline - Attentional cues & $2,92( \pm 3,61)$ & $10,27( \pm 9,32)$ & 0,007 \\
\hline - Self-consoling & $3,17( \pm 3,83)$ & $12,39( \pm 9,91)$ & 0,01 \\
\hline
\end{tabular}

Conclusion SCR/sec, RR, HR and NIDCAP ${ }^{\circledR}$ stress behaviours all significantly increased during the care. Further analyses of the NIDCAP ${ }^{\circledR}$ subgroups identified motor and attentional cues, and ability to self-console as significant.

\section{PO-0725 PSYCHONEUROLOGICAL DEVELOPMENT OF EXTREMELY PREMATURE BABIES}

K Zhumakanova, BA Abeouva, GA Kenzhebayeva, AB Kuzgibekova. Pediatrician and Child Surgery, Karaganda State Medical University, Karaganda, Kazakhstan

\subsection{6/archdischild-2014-307384.1360}

Objective Outcomes of psychoneurological and sensory impairments in extremely premature babies aged less than one year. Materials The analysis of 125 cards of in-patient and out-patient observation of extremely premature babies under specifically designed questionnaires with use of the main indexes of psychological development of premature babies aged less than one year for years 2010, 2011, 2012.

Results and discussion According to our data, only in $16,0 \%$ (2010), 18,8\% (2011) and 23,4\% (2012) of extremely premature babies by one year psychological development corresponded 
to their age, whereas the delay of psychological development rates was noted in 76,5\% (2012), 81,1\% (2011) and 84,0\% (2010) of extremely premature babies. Cerebral palsy developed in 3,7\% (2011), 4,2\% (2012) and 12,0\% (2010). Blindness was observed in 2,1\% (2012), 3,7\% (2011), 8,0\% (2010) of extremely premature babies. Deafness developed in $2,1 \%$ (2012), 3,7\% (2011) and 8,0\% (2010) of extremely premature babies. Epileptiform spasms were observed in 6,3\% (2012), 7,5\% (2011), 12,0\% (2010) of prematurely born babies. Decompensated hydrocephalus developed in 4,2\% (2012), 7,5\% (2011), 16,0\% (2010) of extremely premature babies.

Conclusion Thus, the researches conducted by us show that prematurity is one of risk factors of emergence of neurologic and mental disorders and their prophylaxis, in the first place, is prevention of habitual miscarriage.

\section{Neonatal others}

\section{PO-0725a NEONATAL SCREENING OF AMINOGLYCOSIDE OTOTOXICITY RELATED GENETIC FACTORS IN CHINESE NEONATES}

F Xu. Beijing Pediatric Research Institute, Beijing Children's Hospital, Beijing, China

\subsection{6/archdischild-2014-307384.1361}

Hearing loss is one of the commonest genetic disease which impact human health. There are about $60 \%$ hearing loss patient because of the genetic facters. result of the overlapping factors of genetic predisposition and environmental impact.

Mutations in the mitochondrial $12 \mathrm{~S}$ rRNA gene, particularly the m.1555A $>\mathrm{G}$ have been repeatedly associated with increased susceptibility to the ototoxic effect of aminoglycoside antibiotics such as gentamycin, tobramycin, amikacin, kanamycin, or streptomycin. The Chinese government suggest the children blow 12years old do not to use the aminoglycosides. But the aminoglycoside antimicrobials is the first-line Antimicrobial agents. Aminoglycosides,typically tobramycin, in conjunction with a $\beta$ lactam are the preferred treatment, because there is some evidens indicating that $20 \%$ of Pseudomonas infections are resistant to quinolones (e.g., ciprofloxicin), whereas $4 \%$ are resistant to tobramycin. The mt.1555A $>\mathrm{G}$ mutation is reported to have $100 \%$ penetrance when patients are exposed to aminoglycosides.

We screened the total 17097 neonatal children were included in this study,who were mainly Beijing register and all born in Beijing. 810(4.73\%) children showed the mutation, 51(0.29\%) showed the mutation in mitochondrial $12 \mathrm{~S}$ rRNA. Among them, 47(0.27\%) showed the A1555G mutation and 36/47 appeared to be homoplasmic for this mutation; 3 showed the C1494T mutation and all of them appeared homogeneous mutation. In conclusion, by neonatal screening we considered that screening deafness gene mutations for neonatal before using the aminoglycoside antibiotics is very necessary, that not only avoid the ototoxic, but also make the aminoglycoside antibiotics play a vital role in the clinic.

\section{PO-0725b FLACC IS A VALID AND RELIABLE TOOL AS COMPARED TO THE PIPP FOR ASSESSMENT OF NEONATAL PAIN}

${ }^{1}$ RM Heng, ${ }^{2}$ WB Poon, ${ }^{2}$ SKY Ho. ${ }^{1}$ Yong Loo Lin School of Medicine, National University of Singapore, Singapore, Singapore; ${ }^{2}$ Neonatal and Developmental Medicine, Singapore General Hospital, Singapore, Singapore

10.1136/archdischild-2014-307384.1362
Background Neonates are able to detect and process painful stimuli but are unable to mount a complete response, posing a clinical challenge. Repeated exposure to pain may result in longterm neurodevelopmental sequelae. There is no uniformly agreed method of assessing neonatal pain. Although the "Premature Infants Pain Profile" (PIPP) score is the commonest used worldwide, the "Face, Legs, Activity, Cry and Consolability" (FLACC) score is also often utilised. However, FLACC score has not been validated for infants younger than 2 months old.

Aim To assess validity and reliability of FLACC score in the assessment of neonatal pain responses and collect user feedback. Method A prospective observational study of infants receiving neonatal care in Singapore General Hospital was performed. Painful responses to common procedures were evaluated. Infants were assessed $5 \mathrm{~min}$ before, during and $5 \mathrm{~min}$ after the procedure by 2 independent observers (researcher and nurse), who simultaneously scored the infant using both FLACC and PIPP. User feedback was collected.

Results A total of 53 observations of 30 infants were obtained. FLACC meets criterion validity with a correlation coefficient of 0.641 ( $p$-value $<0.01$ ) and construct validity in 1 known group. FLACC has better inter-rater reliability with kappa value of 0.422 as compared to PIPP, kappa value: 0.221. FLACC received better feedback from nurses, with $89 \%$ preference over PIPP.

Conclusion FLACC is a valid and reliable tool as compared to the PIPP. FLACC received greater clinical acceptance from the nurses, being less cumbersome and not requiring continuous physiologic parameter monitoring.

\section{P0-0725C REFERENCE RANGES OF LIVER AND SPLEEN DIMENSIONS IN TERM INFANTS: SONOGRAPHIC MEASUREMENTS}

${ }^{1} \mathrm{Z}$ Kahramaner, ${ }^{1} \mathrm{~A}$ Erdemir, ${ }^{2} \mathrm{~B}$ Arik, ${ }^{3} \mathrm{G}$ Bilgili, ${ }^{4} \mathrm{M}$ Tekin, ${ }^{4} \mathrm{Y}$ Genc. ${ }^{1}$ Pediatrics Neonatology Clinic, Adiyaman University School of Medicine, Adiyaman, Turkey; ${ }^{2}$ Radiology, Adiyaman University School of Medicine, Adiyaman, Turkey; ${ }^{3}$ Pediatrics Neonatology Clinic, Celal Bayer University School of Medicine, Manisa, Turkey; ${ }^{4}$ Pediatrics, Adiyaman University School of Medicine, Adiyaman, Turkey

\subsection{6/archdischild-2014-307384.1363}

Background and aims To determine reference values of ultrasonographic measurements of the liver and spleen in newborns and to provide a reference chart to use easily in daily practice. Methods In this prospective study, spleen and liver dimensions were evaluated in 384 healthy newborns with a gestation age $\geq 37$ weeks in obstetrics clinic and neonatal intensive care unit with sonography within the first week of life. Relationships of all dimensions with sex, gestational age, height and weight were statistically analysed.

Results No statistically significant differences were found between the two sexes in all dimensions of liver and spleen ( $p>$

Abstract P0-0725 c Table 1 Reference values for liver and spleen dimension

\begin{tabular}{|c|c|c|c|c|c|c|c|c|}
\hline \multirow{2}{*}{ Maximum } & & \multirow[t]{2}{*}{ Mean } & \multirow[t]{2}{*}{ Median } & \multirow[t]{2}{*}{ Minimum } & \multicolumn{4}{|c|}{ Percentile } \\
\hline & & & & & \multicolumn{2}{|c|}{ 5th $\quad 95$ th } & \multirow[b]{2}{*}{53.0} & \multirow[b]{2}{*}{69} \\
\hline \multirow[t]{3}{*}{ Liver (mm) } & Longitudinal & $60.9 \pm 4.9$ & 61.0 & 49.0 & 77.0 & & & \\
\hline & .7 & & & & & & & \\
\hline & $\begin{array}{l}\text { Anteroposterior } \\
.0\end{array}$ & $44.1 \pm 4.5$ & 44.0 & 31.0 & 57.0 & & 38.0 & 52 \\
\hline \multirow[t]{2}{*}{$\begin{array}{l}\text { Spleen } \\
(\mathrm{mm})\end{array}$} & \begin{tabular}{|l} 
Longitudinal \\
.7
\end{tabular} & $38.2 \pm 4.3$ & 38.0 & 28.0 & 54.0 & & 32.0 & 45 \\
\hline & $\begin{array}{l}\text { Anteroposterior } \\
.0\end{array}$ & $21.7 \pm 2.8$ & 22.0 & 15.0 & 29.0 & & 17.0 & 27 \\
\hline
\end{tabular}

